\title{
DISPLACEMENT WASHING OF KRAFT PULP WITH VARIOUS CONSISTENCY
}

\author{
FRANTIŠEK POTU゚ČEK, MOSTAFIZUR RAHMAN* and JOZEF MIKLÍK***
}

\author{
University of Pardubice, Faculty of Chemical Technology, Institute of Chemistry and Technology of \\ Macromolecular Materials, 53210 Pardubice, Czech Republic \\ *Pulp and Paper Research Division, BCSIR Laboratories, Dr. Qudrat-i-Khuda Road, \\ Dhaka 1205, Bangladesh \\ ${ }^{* *}$ HMH, s. r. o., Tavarikova osada 39, 84102 Bratislava, Slovak Republic \\ $₫$ Corresponding author: F. Poti̊ček, frantisek.potucek@upce.cz
}

\author{
Dedicated to the $100^{\text {th }}$ anniversary of the birth of \\ Professor Cristofor Simionescu, the founder of the field of natural and synthetic polymers \\ and of the journal Cellulose Chemistry and Technology
}

\begin{abstract}
The paper deals with the displacement washing of kraft softwood and hardwood pulps with various consistency of the pulp fibre bed. The results obtained revealed differences between the two types of kraft pulp with various morphological properties of fibres. The washing efficiency decreased with decreasing Péclet number for both kraft pulps, but, due to lower longitudinal dispersion of the wash liquid, greater washing efficiency was achieved for the short-fibred hardwood pulp. On the other hand, the long-fibred softwood pulp exhibited lower hydraulic resistance of the pulp fibre bed. The change in pulp consistency and, similarly, the volumetric mass transfer coefficient, characterising the rate of leaching of alkali lignin from pulp fibres, did not have a significant effect on the washing efficiency. However, the mass transfer coefficient decreased with increasing specific resistance of the pulp bed. With increasing bed consistency of both softwood and hardwood pulps, as the amount of black liquor in the inter-fibre pores decreased, the difference between the space time, characterising the holding time of wash liquid, and the mean residence time of alkali lignin increased.
\end{abstract}

Keywords: kraft pulp, softwood, hardwood, displacement washing, pulp consistency

\section{INTRODUCTION}

Pulp washing is an essential process in papermaking. Pulp washing in industrial washers is either a combination of dilution, together with dewatering, and displacement operations as on a drum filter, or essentially, a displacement operation as in a continuous diffuser. ${ }^{1}$ However, using the same amount of wash liquid, the displacement washing is more efficient when the incoming and outgoing consistencies of the pulp are the same. ${ }^{2,3}$

Besides pulp pad thickness, wash liquid velocity and temperature, the pulp pad consistency, i.e., mass of moisture-free fibres per unit volume of uniform bed, can be another key operating variable affecting the displacement washing efficiency. ${ }^{4,5}$ Most of these variables are interrelated, and an improvement in one variable may well have a favourable or unfavourable impact on the others. Moreover, due to the specific properties of the raw wood and the pulping method itself, the pulp is more and less unique. ${ }^{6}$ The influence of the pulp type and the concentration of dissolved substances in the spent liquor, along with fibre pad formation, upon the washing efficiency must be taken into account as well. ${ }^{7}$

The effect of the pulp pad consistency upon the displacement washing efficiency was studied by several authors, but their findings are partially inconsistent. Grähs, ${ }^{8}$ who performed displacement washing experiments for pine kraft pulp with the consistency in the range from 64 to $107 \mathrm{~kg} \mathrm{~m}^{-3}$, found the influence of the fibre consistency profile in the pulp bed on the breakthrough curve. With respect to a completely random arrangement of fibres in pads formed by filtration, Lee ${ }^{9}$ expects 
large local deviations from the average fibre concentration.

Grén and Grähs ${ }^{1}$ found that the wash yield increased with increasing porosity and bed length. Hakamäki and Kovasin, ${ }^{6}$ on the other hand, reported that, in the range from 7 to $12 \%$, high mat consistencies mean higher efficiency of washing. On the contrary, Trinh et $a l^{4,5}$ found that, in the range of 3 to $15 \%$, increasing consistency decreased the washing efficiency for pad thickness greater than $25 \mathrm{~mm}$. Similarly, for fibre mass concentrations varying between 3.5 and $17.3 \%$, Lee ${ }^{9}$ reported a strong tendency toward ideal displacement as fibre concentration decreases. The more effective displacement at low fibre concentration may be attributed both to a decrease in longitudinal mixing between miscible liquids and to a decrease in the portion of stagnant liquor, from which mass transfer must occur by diffusion. Lee ${ }^{9}$ also points out that the stagnant liquor in a pulp pad includes not only a liquor immobilised on the fibre surface and inside the fibre walls, but also an appreciable amount of liquor in inter-fibre pores in regions of high hydraulic resistance, not flowing through the wash liquid.

Considering the contradictory results reported in previous works, ${ }^{1,4-9}$ our study was undertaken to re-examine the effect of pulp consistency upon the efficiency of displacement washing. Laboratory washing experiments were carried out using softwood and hardwood kraft pulps cooked industrially from a blend of spruce and pine and/or hardwoods, respectively. For pulp consistency ranging from 77 to $200 \mathrm{~kg} \mathrm{~m}^{-3}$, the pulp bed characteristics, such as permeability, specific resistance, and equivalent pore diameter, were expressed as a function of the pulp bed consistency. The displacement washing was described mainly by the bed efficiency, axial dispersion coefficient, and mean residence time of alkali lignin, while the leaching operation by the volumetric mass transfer coefficient.

\section{EXPERIMENTAL}

Displacement washing runs simulated under the laboratory conditions were performed in a cylindrical glass cell with an inner diameter of $35 \mathrm{~mm}$ and an adjustable bed height of $30 \mathrm{~mm}$. The fibre pulp bed occupied the space between the permeable septum and a piston, covered with 45 mesh screens to prevent fibre losses from the bed. The pulp beds were not mechanically conditioned and were used as formed.

Pulp beds were formed from a dilute suspension of unbeaten unbleached kraft pulp in the black liquor. Two different pulps, namely a softwood pulp ${ }^{10}$ from spruce and pine in the mass ratio of 3:1 approximately, and a hardwood pulp ${ }^{11}$ from a blend of deciduous trees (beech 55\%, oak 16\%, Turkey oak $8 \%$, acacia $4 \%$, hornbeam $5 \%$, ash $1 \%$, alder $2 \%$, aspen $2 \%$, poplar $6 \%$, and other $1 \%$ ), were produced industrially. The kappa number of both kraft pulps was determined as per the Tappi Test Method T 236 pm-99. The fibre length distribution was measured using a Kajaani FS100 analyser. The effective specific surface of fibres based on fibre volume and mass for both pulps tested was determined according to Ingmanson. ${ }^{12}$ Geometrical characteristics of kraft pulp fibres are given in Table 1.

Black liquors produced after softwood and hardwood kraft cooking were obtained from pulp mills. The solids content of both liquors was determined according to the Tappi Test Method T 211 om-02. The alkali lignin concentration of both black liquors was measured using a Cintra 10e ultraviolet spectrophotometer, at a wavelength of $295 \mathrm{~nm}$. Intrinsic properties of black liquors after softwood and hardwood industrial cooking are summarised in Table 2.

To investigate the displacement washing process, the stimulus-response method was chosen. Distilled water $\left(22{ }^{\circ} \mathrm{C}\right)$ was distributed uniformly through the piston to the top of the bed at the start of the washing experiment, approximating a step change in alkali lignin concentration. At the same time, the displaced liquor was collected at atmospheric pressure from the bottom of the bed through the septum. The washing effluent was sampled at different time intervals and analysed for alkali lignin spectrophotometrically. The displacement washing experiments focusing on the consistency effect upon the washing efficiency were carried out in the pulp consistency range from 77 to $200 \mathrm{~kg} \mathrm{~m}^{-3}$. The procedure of displacement washing with pulp fibres, including the washing equipment, was described in detail in a previous paper. ${ }^{13}$

After completing the washing run, the volumetric flow rate of wash liquid was measured gravimetrically at the pressure drop of $7 \mathrm{kPa}$, to determine the permeability and average effective porosity of the pulp bed. Analogous measurements at various consistencies of the bed were focused on the determination of the effective specific surface of pulp fibres based on fibre mass, $a_{\mathrm{m}}$, and on fibre volume, $a_{\mathrm{V}}$, according to Ingmanson. ${ }^{12}$ The evaluation of the specific fibre surfaces was described in detail earlier. ${ }^{13,14}$ 
Table 1

Geometrical characteristics of pulp fibres

\begin{tabular}{lccccccc}
\hline Pulp & $\begin{array}{c}\text { Kappa } \\
\text { number }\end{array}$ & $\begin{array}{c}\text { Arithmetic } \\
\text { average } \\
\text { length, mm }\end{array}$ & $\begin{array}{c}\text { Weighted } \\
\text { average } \\
\text { length, } \mathrm{mm}\end{array}$ & $\begin{array}{c}\text { Polydispersity } \\
\text { of fibre } \\
\text { length }\end{array}$ & $\begin{array}{c}\text { Fibre } \\
\text { coarseness, } \\
\mathrm{mg} \mathrm{m}^{-1}\end{array}$ & $\begin{array}{c}\text { Specific } \\
\text { surface, } \\
\mathrm{cm}^{-1} \mathrm{~m}^{2} \mathrm{~kg}^{-1}\end{array}$ \\
\hline Softwood & 24.9 & 1.22 & 2.19 & 1.8 & 0.167 & 1920 & 557 \\
Hardwood & 29.9 & 0.749 & 0.899 & 1.2 & 0.370 & 3380 & 983 \\
\hline
\end{tabular}

Table 2

Intrinsic properties of black liquors after softwood and hardwood cooking

\begin{tabular}{lcccccc}
\hline Black liquor & $\mathrm{pH}$ & $\begin{array}{c}\text { Density }\left(22{ }^{\circ} \mathrm{C}\right), \\
\mathrm{kg} \mathrm{m}^{-3}\end{array}$ & $\begin{array}{c}\text { Total solids, } \\
\text { mass \% }\end{array}$ & $\begin{array}{c}\text { Inorganics, } \\
\text { mass \% }\end{array}$ & $\begin{array}{c}\text { Organics, } \\
\text { mass \% }\end{array}$ & $\begin{array}{c}\text { Lignin, } \\
\mathrm{kg} \mathrm{m}^{-3}\end{array}$ \\
\hline Softwood & 12.6 & 1097 & 21.4 & 13.7 & 7.7 & 56 \\
Hardwood & 12.2 & 1071 & 15.3 & 5.7 & 9.6 & 27 \\
\hline
\end{tabular}

\section{Treatment of experimental data Pulp fibre bed characteristics}

According to Darcy's law, the superficial velocity of the wash liquid flowing through the porous pulp bed is given as:

$$
u=B \frac{\Delta P}{\mu h}
$$

where $\Delta P$ is the pressure difference, $h$ is the bed thickness, and $\mu$ is the liquid viscosity. The permeability, $B$, is a measure of the liquid conductivity through the porous bed. ${ }^{15}$

By assuming that the pore network consists of many distinct, continuous, and regular channels, the permeability can be expressed using the well-known classical macroscopic Kozeny-Carman equation in the form:

$$
B=\frac{\mathcal{E}^{3}}{(1-\varepsilon)^{2} a_{\mathrm{V}}^{2} K}
$$

where $\varepsilon$ is the average effective bed porosity defined as the ratio of the volume of the pore space open to flow to the volume of the porous pulp bed, ${ }^{16}$ and $a_{\mathrm{V}}$ is the specific surface of fibres. The Kozeny constant, $K$, depending only upon the shape of pores and the ratio of the tortuous length that liquid traverses in passing through the bed to the actual bed thickness has an average value of 5.55 for randomly packed fibre beds. $^{12,16}$

If the mass of fibres in the bed $m_{\mathrm{F}}=h A \rho_{\mathrm{F}}$, where $A$ is the cross-sectional area and $\rho_{\mathrm{F}}$ is the consistency of pulp, then the average specific bed resistance, $\alpha=$ $\left(B \rho_{\mathrm{F}}\right)^{-1}\left(\right.$ ref. $\left.^{17}\right)$, may be written as:

$\alpha=\frac{(1-\varepsilon)^{2} a_{\mathrm{V}}^{2} K}{\mathcal{E}^{3} \rho_{\mathrm{F}}}$

The average specific bed resistance, $\alpha$, is a measure of the resistance offered by the fibre bed to the flow of the wash liquid.
If the Kozeny-Carman equation (2) is applicable for the flow through a porous bed, ${ }^{18}$ the equivalent pore diameter:

$$
d_{\mathrm{eq}}=\sqrt{\frac{200 u \mu h}{3 \varepsilon \Delta P}}
$$

can be calculated in the streamline flow regime.

\section{Mass transfer}

Owing to the displacement and leaching mechanisms acting simultaneously, the total mass transfer in the unit volume of the pulp bed $\left(\mathrm{kg} \mathrm{s}^{-1} \mathrm{~m}^{-3}\right)$ may be described by the following equation: ${ }^{19}$

$u \frac{\mathrm{d} \rho}{\mathrm{d} H}=\frac{u}{h}\left(\rho-\rho_{\mathrm{i}}\right)+k_{\mathrm{L}} a\left(\rho_{\mathrm{avg}}-\rho_{\mathrm{i}}\right)_{\mathrm{m}}$

where $\rho$ is the solute concentration within the bed (in $\mathrm{kg} \mathrm{m}^{-3}$ ), depending on the vertical coordinate, $H$, at a given time, $k_{\mathrm{L}} a$ is the average volumetric mass transfer coefficient (in s $\left.{ }^{-1}\right)$, and $\left(\rho_{\mathrm{avg}}-\rho_{\mathrm{i}}\right)_{\mathrm{m}}$ is the mean driving force given as the difference between average solute concentration within the bed and solute concentration in the wash liquid.

The time dependence of solute removal from the pulp fibre bed recorded as the breakthrough washing curve enables to characterise the displacement washing in terms of the dimensionless Péclet number derived from the mass balance of the solute, ${ }^{20}$ in our case alkali lignin, for a given system in unsteady state, as:

$P e=\frac{h u}{D \varepsilon}$

where $D$ is the longitudinal dispersion coefficient. The evaluation of the Péclet number from the breakthrough curves was described in detail in previous works. ${ }^{13,20-22}$ The washing breakthrough curves for softwood and hardwood pulps were published in preceding papers. $^{11,23}$

The efficiency of displacement, $E_{\mathrm{RW}=1}$, may be expressed by the following relationship ${ }^{13,19}$ in the form:

$E_{\mathrm{RW}=1}=-\ln \left(1-W Y_{\mathrm{RW}=1}\right)$ 
where the traditional wash yield for the wash liquor ratio equal to unity, $W Y_{\mathrm{RW}=1}$, is defined as:

$W Y_{\mathrm{RW}=1}=\frac{\int_{R W=0}^{R W=1} \frac{\rho_{\mathrm{e}}}{\rho_{0}} \mathrm{~d}(R W)}{\int_{R W=0}^{R W} \frac{\rho_{\mathrm{e}}}{\rho_{0}} \mathrm{~d}(R W)}$

where $R W$ is the wash liquor ratio, defined as the mass of wash liquid passed through the bed to the given time divided by the mass of mother liquor originally present in the bed, $\rho_{\mathrm{e}}$ is the exit lignin concentration and $\rho_{0}$ is the initial lignin concentration in the bed at $R W=0$.

The mean residence time of the solute in the pulp bed, $t_{\mathrm{m}}$, is defined as:

$t_{\mathrm{m}}=\int_{t=0}^{t \rightarrow \infty} \frac{\rho_{\mathrm{e}}}{\rho_{0}} \mathrm{~d} t$

The space time, $\tau$, characterising the holding time of the wash liquid in the pulp bed, is defined as:

$\tau=\frac{h \varepsilon}{u}$

As soon as the black liquor is displaced from interfibre pores, the leaching of the solute from fibre walls begins. The intensity of mass transfer by leaching may be characterised by a volumetric mass transfer coefficient, $k_{\mathrm{L}} a$, as a product of the mass transfer coefficient and the specific interfacial area. ${ }^{24}$

\section{RESULTS AND DISCUSSION \\ Pulp bed characteristics}

First, the influence of the change in consistency within the limits of 77 to $200 \mathrm{~kg} \mathrm{~m}^{-3}$ on the hydraulic properties of the pulp fibre bed will be discussed in the framework of our experimental conditions. As can be generally expected, as the pulp consistency decreased, the average flow porosity of the pulp bed increased from 0.47 to 0.74 , with an average of 0.61 , and from 0.32 to 0.59 , with an average of 0.48 , for softwood and hardwood pulps, respectively. A

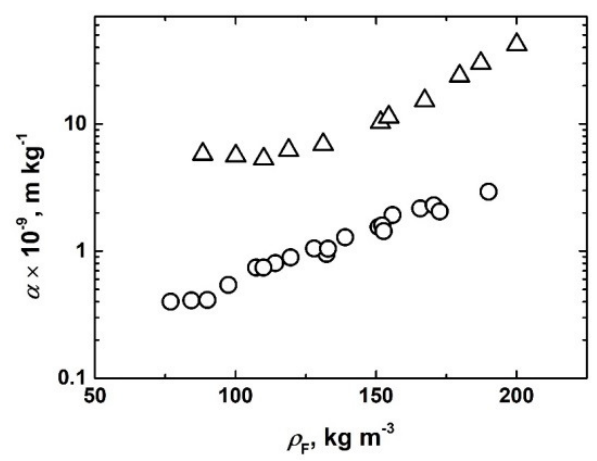

Figure 1: Specific bed resistance as a function of pulp consistency; pulps: $\bigcirc$ softwood, $\Delta$ hardwood change in the average flow porosity resulted in the specific hydraulic resistance of the pulp bed, which increases with increasing pulp consistency (Fig. 1). However, larger values of specific resistance were unambiguously achieved for short-fibred hardwood pulp, comparing to longfibred softwood pulp ( $c f$. fibre length in Table 1).

From Figure 2, it follows that as the specific hydraulic resistance of the fibre bed increases with increasing consistency, the permeability of the wash liquid decreases. The Reynolds number, $R e$ (defined in Symbols), ranging from $5 \times 10^{-4}$ to $2.4 \times 10^{-2}$, confirms unambiguously the laminar flow regime of the wash water flowing through the pulp fibre bed when Darcy's law (Eq. (1)) holds.

A similar trend to that of permeability is shown by equivalent pore diameter (Fig. 3), which with increasing consistency decreases from 62 to $18 \mu \mathrm{m}$ and from 15 to $5 \mu \mathrm{m}$ for softwood and hardwood pulps, respectively. It is worth mentioning that, in the consistency range from 100 to $170 \mathrm{~kg} \mathrm{~m}^{-3}$ for softwood pulp, and from 80 to $130 \mathrm{~kg} \mathrm{~m}^{-3}$ for hardwood pulp approximately, the equivalent pore diameter corresponds roughly to the width of fibres of the coniferous and deciduous woods, respectively.

All three parameters, namely the specific hydraulic resistance, permeability, and equivalent pore diameter, thus gave consistent results, describing the effect of pulp consistency on the hydraulic properties of the pulp fibre bed. At the same time, it was unambiguously confirmed that short-fibred hardwood pulp exhibits greater hydraulic resistance, accompanied by a smaller pore diameter and less permeability of the wash liquid.

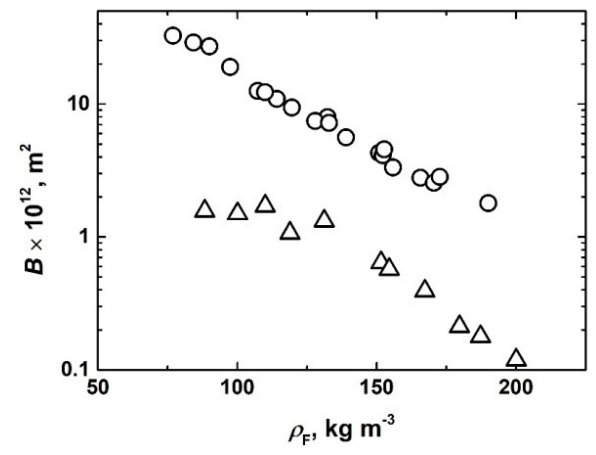

Figure 2: Permeability as a function of pulp consistency; pulps: $\bigcirc$ softwood, $\Delta$ hardwood 


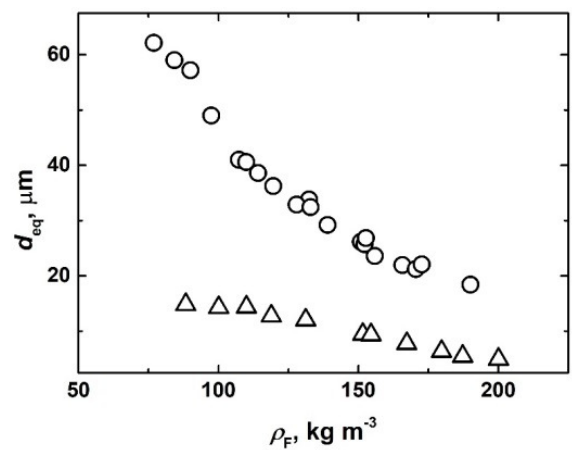

Figure 3: Equivalent pore diameter as a function of pulp consistency; pulps: $\bigcirc$ softwood, $\Delta$ hardwood

\section{Washing efficiency}

The packed bed of pulp fibres is assumed to consist of porous, compressible pulp fibres and liquor, which is located inside the inter-fibre pores, the so-called free liquor, and in close contact with the fibres, the so-called immobile liquor. While the free liquor is predominantly easily displaced by the wash liquid, the immobile liquor can be removed only by the diffusion transport, which is a relatively slow process. As soon as the mother liquor inside the pores is displaced by the wash liquid, the leaching of solutes from the stagnant liquor immobilised on the surface and inside fibre walls begins.

Thus, displacement washing consists in displacement and leaching, which takes place when the concentration driving force exists. Moreover, due to a completely random arrangement of fibres, the labyrinth of inter-fibre pores with different diameter and space orientation has a significant influence upon the course of displacement. Therefore, besides the variable pulp consistency, $\rho_{\mathrm{F}}$ (in $\mathrm{kg} \mathrm{m}^{-3}$ ), the effect of the Péclet number defined by Equation (6) and volumetric mass transfer coefficient, $k_{\mathrm{L}} a$ (in $\mathrm{s}^{-1}$ ), characterising the intensity of leaching on the washing efficiency was also assumed.

Based on the data measured for both types of kraft pulp, the following correlation:

$$
E_{\mathrm{RW}=1}=1.84 P e^{0.113} k_{\mathrm{L}} a^{0,0397} \rho_{\mathrm{F}}^{-0.0305}
$$

for the bed efficiency at $R W=1, E_{\mathrm{RW}=1}$, was calculated with the mean relative deviation of $4.1 \%$ and the Akaike information criterion of -145 . The $95 \%$ confidence intervals for the coefficient and for the power of the Péclet number, $P e$, volumetric mass transfer coefficient, $k_{\mathrm{L}} a$, and consistency, $\rho_{\mathrm{F}}$, were $(1.75 ; 1.93)$, (0.109; 0.117), (0.0354; 0,0440), and (-0.0415; $-0.0195)$, respectively. Hence, a satisfactory agreement was found between the experimental and the calculated data.

A deeper analysis of the measured data revealed that the bed efficiency is mainly influenced by the breakthrough curve profile, which determines the value of the Péclet number. The bed efficiency also increases with greater leaching intensity given by the volumetric mass transfer coefficient. A similar effect on the washing efficiency to that of leaching is exhibited by the decrease in pulp consistency. However, the last two variables have a much slighter effect on the washing efficiency than the Péclet number.

Since the influence of the volumetric mass transfer coefficient and pulp consistency on the bed efficiency is not marked, Equation (11) can be expressed approximately in the form:

$$
E_{R W=1}=4.28 L_{D}^{-0.179}
$$

as the dependence of the bed efficiency on the dimensionless dispersion length, ${ }^{25} L_{\mathrm{D}}$, defined in Symbols, with the mean relative deviation of $4.1 \%$ and the Akaike information criterion of -151 . The $95 \%$ confidence intervals for the coefficient and power at the dispersion length were $(4.14 ; 4.41)$ and $(-0.185 ;-0.172)$, respectively.

Since the dimensionless dispersion length, $L_{\mathrm{D}}$ $=a_{\mathrm{V}} D \varepsilon / 4 u$, is directly proportional to the axial dispersion coefficient, $D$, the bed efficiency decreases with decreasing Péclet number, i.e., with increasing dispersion length, as illustrated in Figure 4. Although the Péclet number calculated on the basis of the washing curves ${ }^{13}$ varied significantly for softwood and hardwood pulps, 5.3-11.6 and 21.4-44.7, respectively, a satisfactory fit was obtained between Equation (12) and the plot of $E_{\mathrm{RW}=1} v s . L_{\mathrm{D}}$.

Due to the random arrangement of pulp fibres, the difference in the space orientation of inter- 
fibre pores and their size distribution occurring in the unmovable pulp bed influenced the axial dispersion of the flow of the wash liquid. It is obvious from Figure 5 that the dependence of the dispersion coefficient on the superficial wash liquid velocity shows an increasing trend for both types of kraft pulp, similarly as in the case of nonporous granular particles. ${ }^{13,26}$

The dependence of the dispersion coefficient, $D$ (in $\mathrm{m}^{2} \mathrm{~s}^{-1}$ ), calculated from the Péclet number defined by Equation (6), on the superficial wash liquid velocity, $u$ (in $\mathrm{m} \mathrm{s}^{-1}$ ), may be correlated by a straight-line relationship as follows:

$D=6.00 \times 10^{-3} u$

with a correlation coefficient of 0.89 for kraft softwood pulp, and

$D=1.78 \times 10^{-3} u$

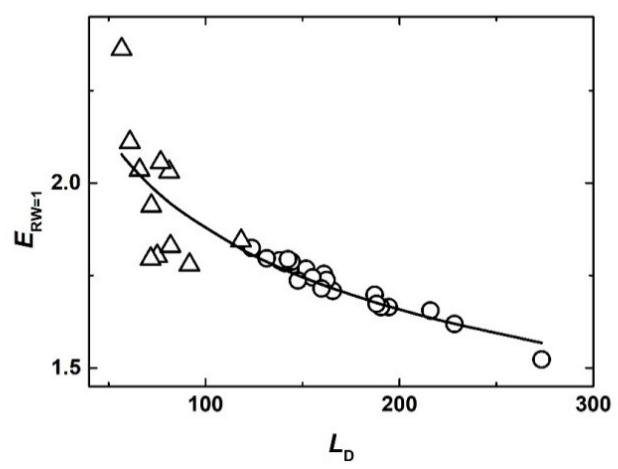

Figure 4: Influence of dispersion length on bed efficiency; pulps: $\bigcirc$ softwood, $\Delta$ hardwood; solid line: Eq. (12)

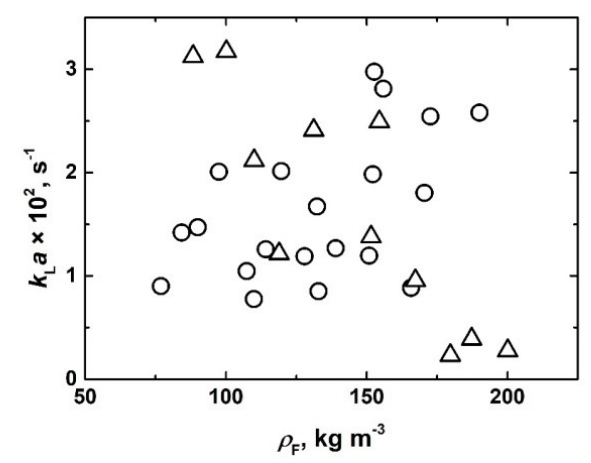

Figure 6: Dependence of volumetric mass transfer coefficient on pulp consistency; pulps: $\bigcirc$ softwood, $\Delta$ hardwood

\section{Leaching}

The leaching intensity in the unit volume of fibre bed can be characterised by the volumetric with a correlation coefficient of 0.92 for kraft hardwood pulp.

Although Equations (13) and (14) were derived for the data obtained in a relatively wide range of consistency, they strongly agree with the previous results reported for softwood ${ }^{27}$ and hardwood ${ }^{11}$ kraft pulps with a small consistency range from 11.8 to $13.9 \%$ and of 10.8 to $11.8 \%$, respectively. However, the dispersion coefficient measured for the pulp fibres is greater than that of the non-porous solid monodisperse particle beds. ${ }^{13,26,27}$ Larger values of the dispersion coefficient found for softwood pulp had a negative impact on the bed efficiency compared to hardwood pulp. It is likely that the increase in the dispersion coefficient can be attributed to greater polydispersity of the long-fibred softwood pulp, compared to that of the short-fibred hardwood pulp ( $c f$. Table 1).

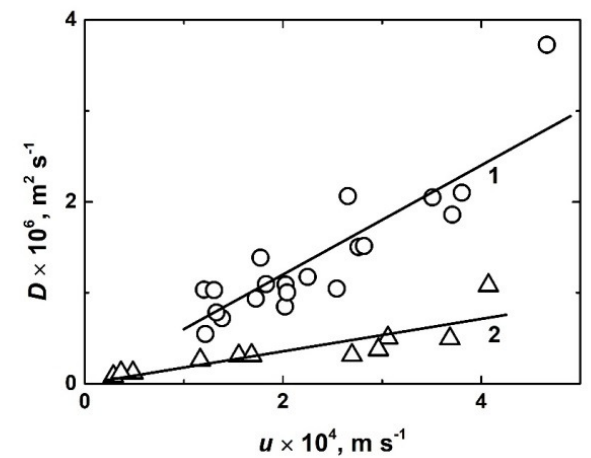

Figure 5: Dependence of dispersion coefficient on superficial wash liquid velocity; pulps: $\bigcirc$ softwood, $\Delta$ hardwood; solid line: 1 Eq. (13), 2 Eq. (14)

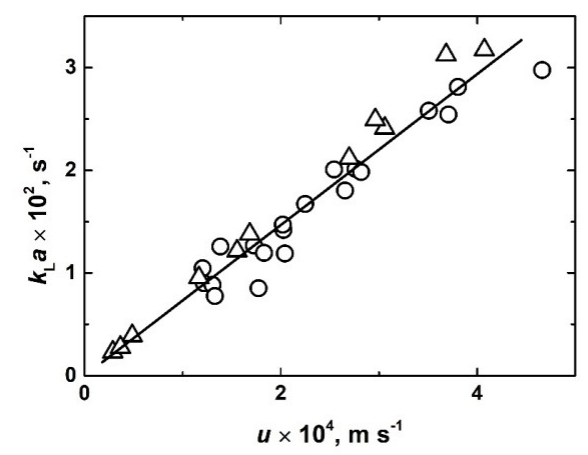

Figure 7: Dependence of volumetric mass transfer coefficient on superficial wash liquid velocity; pulps: $\bigcirc$ softwood, $\Delta$ hardwood; solid line: Eq. (15)

mass transfer coefficient, the evaluation of which was described in detail in the previous paper. ${ }^{24}$ The volumetric mass transfer coefficient, $k_{\mathrm{L}} a$, is a 
product of the mass transfer coefficient, $k_{\mathrm{L}}$, and of interfacial area, $a$, available for mass transfer in the unit volume of the pulp bed. Assuming that the interfacial area is directly proportional to surface of fibres, the consistency of the pulp should affect the intensity of mass transfer by leaching.

From Figure 6, it follows that, although the volumetric mass transfer coefficient also depends on the interfacial area, which increases with increasing consistency of the pulp fibre bed, the unambiguous dependence of the volumetric mass transfer coefficient on the pulp consistency is not clearly apparent. However, in spite of the considerable scatter in the data, it can be deduced that, while for hardwood pulp, with increasing pulp consistency, a decreasing trend of leaching intensity appears, the opposite seems to be true for softwood pulp.

The dependence of the volumetric mass transfer coefficient on the superficial wash liquid velocity illustrated in Figure 7 does not indicate any apparent differences between the two types of pulp investigated in the present work. Hence, the dependence of $k_{\mathrm{L}} a\left(\right.$ in $\left.\mathrm{s}^{-1}\right) v s . u$ (in $\mathrm{m} \mathrm{s}^{-1}$ ) can be satisfactorily fitted by a straight-line relationship in the form:

$k_{\mathrm{L}} a=73.4 u$

with a correlation coefficient of 0.973 .

The results expressed by Equation (15) are in good agreement with those obtained for the

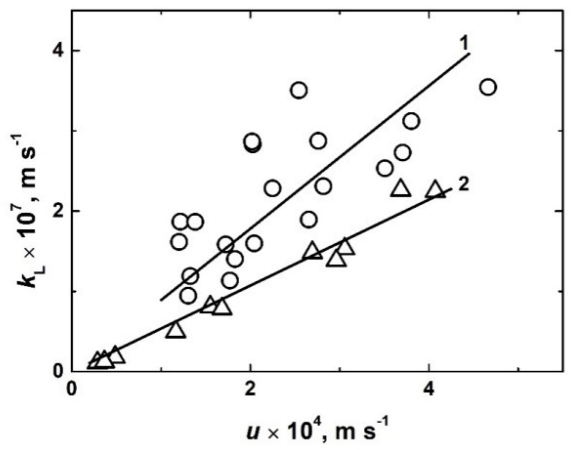

Figure 8: Dependence of mass transfer coefficient on superficial wash liquid velocity; pulps: $\bigcirc$ softwood, $\Delta$ hardwood; solid line: 1 Eq. (16), 2 Eq. (17) spruce kraft pulp in the previous paper. ${ }^{24}$ It is worth noting that the values of the volumetric mass transfer coefficient are of the same order of magnitude as those measured for oxygen transfer during batch cultivation in an airlift tower fermentor. ${ }^{28}$

Under simplifying assumptions that the interfacial area in the unit volume of pulp bed may be expressed as $a \approx(1-\varepsilon) a_{\mathrm{V}}$, the mass transfer coefficient, $k_{\mathrm{L}}$, may be estimated. Despite the simplified approach to determining the mass transfer coefficient, it is obvious from Figure 8 that the mass transfer coefficient increases with increasing superficial wash liquid velocity for both kraft pulps tested, although in the case of the softwood pulp the data manifest a relatively large scatter. An increase in the mass transfer coefficient is related to faster convective transport of leached substances away from the fibre surface as the wash liquid velocity in the inter-fibre pores increases.

The correlation equations between the mass transfer coefficient, $k_{\mathrm{L}}$ in $\mathrm{m} \mathrm{s}^{-1}$, and the wash liquid velocity, $u$ in $\mathrm{m} \mathrm{s}^{-1}$, were derived in the form:

$$
\begin{aligned}
& k_{\mathrm{L}}=0.890 \times 10^{-3} u \\
& k_{\mathrm{L}}=0.536 \times 10^{-3} u
\end{aligned}
$$

with a correlation coefficient of 0.638 and 0.985 for softwood and hardwood pulps, respectively.

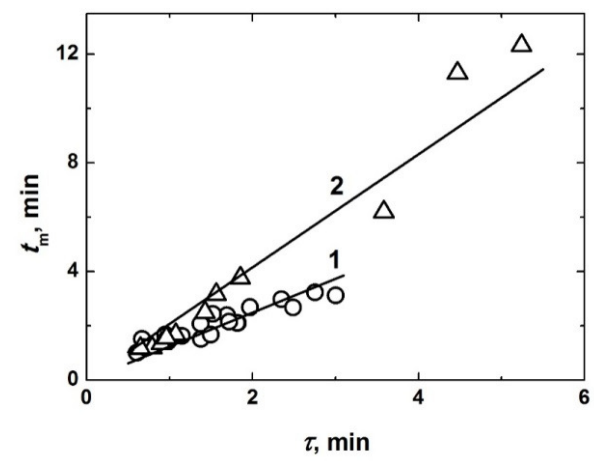

Figure 9: Dependence of mean residence time on space time; pulps: $\bigcirc$ softwood, $\Delta$ hardwood; solid line: 1 Eq. (18), 2 Eq. (19) 


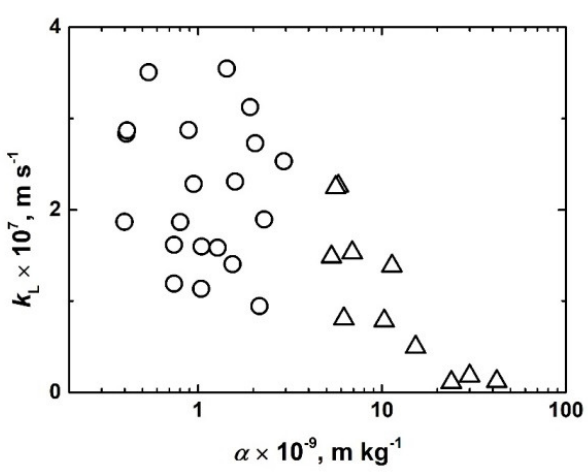

Figure 10: Dependence of mass transfer coefficient on specific hydraulic resistance of pulp bed; pulps: $\bigcirc$ softwood, $\Delta$ hardwood

The lower leaching rate of alkali lignin in the hardwood pulp, resulting in lower mass transfer coefficient $k_{\mathrm{L}}$ (Fig. 8), may be related to a longer mean residence time of the alkali lignin macromolecules in the fibre bed, compared to the softwood pulp ( $c f$. Fig. 9). The dependence of the mean residence time of alkali lignin in the pulp bed, $t_{\mathrm{m}}$ (in $\mathrm{min}$ ), on the space time, $\tau$ (in $\mathrm{min}$ ), proportional to the holding time of the wash water in the pulp bed, can be expressed as:

$t_{\mathrm{m}}=1.24 \tau$

$t_{\mathrm{m}}=2.18 \tau$

with a correlation coefficient of 0.877 and 0.976 for softwood and hardwood pulps, respectively.

While the volumetric mass transfer coefficient of both types of kraft pulp does not appear to differ due to the larger specific surface of the hardwood fibres ( $c f$. Table 1), the mass transfer coefficient, $k_{\mathrm{L}}$, during leaching from hardwood fibres is unambiguously smaller, compared to the softwood fibres, which is confirmed by significantly larger differences between the mean residence time and the space time for hardwood fibres.

Figure 10 shows the effect of the specific resistance of the pulp bed on the mass transfer coefficient. Predominantly greater values of the mass transfer coefficient were related to the lower specific hydraulic resistance of the softwood pulp bed, in comparison with the hardwood pulp. However, the decrease in the mass transfer coefficient with increasing specific resistance of the pulp bed is quite obvious, especially for shortfibred hardwood pulp.

As follows from Equation (11), the effect of a change in pulp consistency on the washing

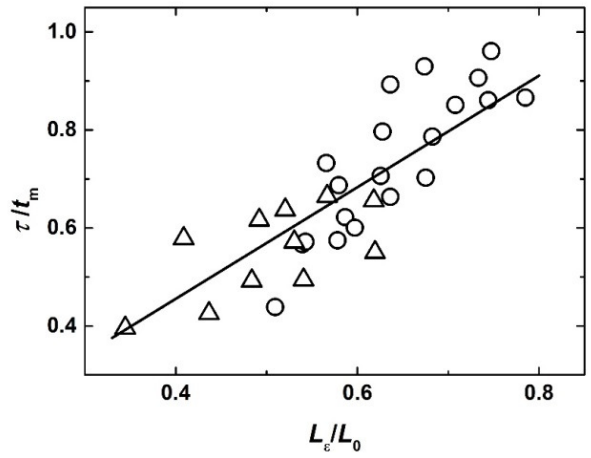

Figure 11: Dependence of space time and mean residence time ratio, $\tau / t_{\mathrm{m}}$, on mass of free liquor and mass of total liquor ratio, $L_{\varepsilon} / L_{0}$; pulps: $\bigcirc$ softwood, $\Delta$ hardwood; solid line: Eq. (20)

efficiency is not significant. Generally, with decreasing pulp consistency, the amount of liquor in the inter-fibre pores available to displace by the wash liquid increases. As mentioned earlier, ${ }^{29}$ the ratio between the amount of free liquor in the inter-particle pores to the total liquor in the pulp bed, $L_{\varepsilon} / L_{0}$, is reflected in the relationship between the space time and the mean residence time of alkali lignin in the bed, $\tau / t_{\mathrm{m}}$. The dependence of $\tau / t_{\mathrm{m}}$ vs. $L_{\varepsilon} / L_{0}$ shown in Figure 11 was satisfactorily fitted by the following equation:

$\tau / t_{\mathrm{m}}=1.14 L_{\varepsilon} / L_{0}$

with a correlation coefficient of 0.855 .

For the unmovable bed from non-porous particles, where the liquor is located only in the inter-particle pores, the mean residence time is approximately equal to the space time, as confirmed in a previous paper. ${ }^{13}$ However, if the displacement process is accompanied by leaching from within fibre walls, the space time appears to be directly proportional to the mass of liquor in the void volume of the pulp bed, while the mean residence time corresponds to the total mass of liquor in the bed, in agreement with the results obtained for the washing of kraft softwood pulp with aqueous urea solutions reported earlier. ${ }^{29}$

\section{CONCLUSION}

Since the pulp consistency is considered to be one of the important variables influencing washing efficiency, the displacement washing of softwood and hardwood kraft pulps was studied at various pulp consistencies ranging from 77 to 200 $\mathrm{kg} \mathrm{m}^{-3}$. In the framework of the present study, the following conclusions can be drawn.

As expected, as the consistency of the pulp fibre bed increases, its hydraulic resistance 
increases and the equivalent diameter of the interfibre pores decreases. However, short-fibred hardwood pulp exhibits greater hydraulic resistance, accompanied by a smaller equivalent pore diameter than long-fibred softwood pulp.

Based on the results obtained, it is obvious that a decrease in pulp consistency has only a slight effect on the washing efficiency increase. The efficiency of displacement washing is dependent primarily on the inhomogeneity of the pulp fibre bed, having an impact on the shape of the breakthrough washing curve. Thus, the most considerable effect on the washing efficiency is mainly exerted by the Péclet number. For both kraft pulps, the washing efficiency unambiguously decreases with increasing dispersion length, indirectly proportional to the Péclet number.

The washing efficiency is slightly affected by the leaching intensity of lignin in the unit volume of the pulp bed, but the volumetric mass transfer coefficient increases with increasing velocity of the wash liquid for both types of kraft pulp. However, the mass transfer coefficient estimated on the basis of the volumetric coefficient was found to be lower for hardwood fibres, which is associated with a longer mean residence time of lignin in the bed compared to softwood fibres.

\section{SYMBOLS}

A cross-sectional area of pulp bed, $\mathrm{m}^{2}$ a specific interfacial area per unit volume of pulp bed, $\mathrm{m}^{-1}$

$a_{\mathrm{V}} \quad$ specific surface of pulp fibres based on fibre volume, $\mathrm{m}^{-1}$

$B \quad$ permeability, $\mathrm{m}^{2}$

$D \quad$ axial dispersion coefficient, $\mathrm{m}^{2} \mathrm{~s}^{-1}$

$d_{\mathrm{eq}} \quad$ equivalent pore diameter defined by Eq.

(4), m

$E_{\mathrm{RW}=1} \quad$ bed efficiency at $R W=1$ defined by Eq. (7), dimensionless

$H \quad$ vertical distance from top of bed, $\mathrm{m}$

$h \quad$ bed thickness, $m$

$K \quad$ Kozeny constant in Eqs. (2) and (3), dimensionless

$k_{\mathrm{L}} \quad$ mass transfer coefficient, $\mathrm{m} \mathrm{s}^{-1}$

$k_{\mathrm{L}} a \quad$ volumetric mass transfer coefficient, $\mathrm{s}^{-1}$

$L_{\mathrm{D}} \quad$ dispersion length $\left(=h a_{\mathrm{V}} / 4 P e\right)$, dimensionless

$L_{\varepsilon} \quad$ mass of liquor in void volume of pulp bed, $\mathrm{kg}$

$L_{0} \quad$ mass of liquor in pulp bed at $R W=0, \mathrm{~kg}$

$\Delta P \quad$ pressure drop, $\mathrm{Pa}$
Pe Péclet number based on the thickness of the bed and defined by Eq. (6), dimensionless

$R e$ dimensionless

$R W \quad$ wash liquor ratio, dimensionless

$t \quad$ time, s

$t_{\mathrm{m}} \quad$ mean residence time defined by Eq. (9), $\min$

$u \quad$ superficial wash liquid velocity, $\mathrm{m} \mathrm{s}^{-1}$

$W Y_{\mathrm{RW}=1}$ wash yield at $R W=1$ defined by Eq. (8), dimensionless

\section{Greek letters}

$\alpha \quad$ average specific bed resistance defined by Eq. (3), $\mathrm{m} \mathrm{kg}^{-1}$

$\varepsilon \quad$ average effective flow porosity of packed bed, dimensionless

$\mu \quad$ liquid viscosity, $\mathrm{Pa} \mathrm{s}$

$\rho \quad$ local solute concentration within pulp bed, $\mathrm{kg} \mathrm{m}^{-3}$

$\rho_{\text {avg }} \quad$ average solute concentration within pulp bed, $\mathrm{kg} \mathrm{m}^{-3}$

$\rho_{\mathrm{e}} \quad$ exit solute concentration in outlet stream of liquor, $\mathrm{kg} \mathrm{m}^{-3}$

$\rho_{\mathrm{F}} \quad$ consistency of pulp, $\mathrm{kg} \mathrm{m}^{-3}$

$\rho_{\mathrm{i}} \quad$ solute concentration in wash liquid, in $\mathrm{kg} \mathrm{m}^{-3}$

$\rho_{\mathrm{WL}} \quad$ density of wash liquid, $\mathrm{kg} \mathrm{m}^{-3}$

$\rho_{0} \quad$ initial solute concentration in bed at $R W$ $=0, \mathrm{~kg} \mathrm{~m}^{-3}$

$\tau \quad$ space time defined by Eq. (10), min

ACKNOWLEDGEMENTS: This work was supported by the Ministry of Education, Youth, and Sports of the Czech Republic under the research project SGS_2020_007.

\section{REFERENCES}

1 U. Grén and L.-E. Grähs, Svensk Papperstidn., 76, $597 \quad$ (1973), http://spt.spci.se/contact; https://www.ssg.se/om-ssg/press-och-media/

2 R. H. Crotogino, N. A. Poirier and D. T. Trinh, $\begin{array}{lllll}\text { Tappi } & \text { J., } & \mathbf{7 0}, & 95 & \text { (1987), }\end{array}$ https://www.tappi.org/Search/?srchtext=publisher

3 R. B. Santos and P. W. Hart, Tappi J., 13, 9 (2014), https://www.tappi.org/Search/?srchtext=publisher

4 D. T. Trinh, N. A. Poirier and R. H. Crotogino, in Procs. Pulp Washing Symposium, Finnish Pulp and Paper Research Institute, Finland, May 18-21, 1987

5 D. T. Trinh, N. A. Poirier, R. H. Crotogino and W. J. M. Douglas, J. Pulp Paper Sci., 15, J28 (1989), http://www.paptac.ca/en/component/docman/

6 H. Hakamäki and K. Kovasin, Pulp Pap. Can., 86, $\mathrm{T} 243$ (1985), 


\section{FRANTIŠEK POTU゚ČEK et al.}

7 L.-E. Grähs, Svensk Papperstidn., 79, 84 (1976), http://spt.spci.se/contact; https://www.ssg.se/omssg/press-och-media/

8 L.-E. Grähs, Svensk Papperstidn., 79, 123 (1976), http://spt.spci.se/contact; https://www.ssg.se/omssg/press-och-media/

9 P. F. Lee, Tappi J., 62, 75 (1979), https://www.tappi.org/Search/?srchtext=publisher

10 F. Potůček and M. Rahman, Acta Facult. Xylol. Zvolen, 61, 51 (2019), https://df.tuzvo.sk/sk/actafacultatis-xylologiae-zvolen

11 F. Potůček and J. Miklík, Chem. Pap., 64, 147 (2010), https://doi.org/10.2478/s11696-009-0078-7

12 W. L. Ingmanson, Chem. Eng. Prog., 49, 577 (1953),

https://www.scimagojr.com/journalsearch.php?q=Ame rican Institute of Chemical Engineers \& tip=pub

13 F. Potůček, Collect. Czech. Chem. Commun., 62, 626 (1996), https://doi.org/10.1135/cccc19970626

14 F. Potůček and M. Marhanová, Sci. Papers Univ. Pardubice, Ser. A, 4, 223 (1998), https://fcht.upce.cz/fcht/vedavyzkum/casopisy/scientific.html

15 R. B. Bird, W. E. Steward and E. N. Lightfoot, "Transport Phenomena", Academia, Praha, 1968 (in Czech)

16 J. D. Lindsay, Tappi J., 77, 225 (1994), https://www.tappi.org/Search/?srchtext=publisher

17 A. J. M. Herwijn, E. J. L. Heij, J. J. Ijzermans, W. J. Coumans and P. J. A. M. Kerkhof, Ind. Eng. Chem. Res., 34, $1310 \quad$ (1995), https://pubs.acs.org/journal/iecred

18 W. L. McCabe, J. C. Smith and P. Harriott, "Unit Operations of Chemical Engineering", $6^{\text {th }}$ ed., McGraw-Hill, Boston, 2001
19 H. T. Cullinan, Appita J., 44, 91 (1991), https://appita.com/publication-resources/appitamagazine-appita-peer-reviewed-journal

20 F. Potůček, Pap. Celul., 56, 8 (2001), http://www.svettisku.cz/buxus/generate_page.php?pag e id $=6869 \&$ \&uxus_svettisku=

${ }^{21}$ O. Levenspiel, "Chemical Reaction Engineering", John Wiley \& Sons, New York, 1962

22 E. T. van der Laan, Chem. Eng. Sci., 7, 187 (1957), https://www.elsevier.com/

23 F. Potůček, Cellulose Chem. Technol., 53, 333 (2019), https://doi.org/10.35812/CelluloseChemTechnol.2019. 53.33

24 F. Potůček, Cellulose Chem. Technol., 53, 929 (2019), https://doi.org/10.35812/CelluloseChemTechnol.2019. 53.90

25 E. Mauret and M. Renaud, Appita J., 55, 123 (2002), https://appita.com/publicationresources/appita-magazine-appita-peer-reviewedjournal

26 W. R. Sherman, AIChE J., 10, 855 (1962), https://aiche.onlinelibrary.wiley.com/journal/15475905 ${ }^{27}$ F. Potůček and M. Pulcer, Chem. Pap., 58, 377 (2004),

https://www.chempap.org/file_access.php?file=586a37 7.pdf

28 F. Potůček, Collect. Czech. Chem. Commun., 54, 3213 (1989), https://doi.org/10.1135/cccc19893213

29 F. Potůček and M. Pulcer, Chem. Pap., 60, 365 (2006), https://doi.org/10.2478/s11696-006-0066-0 